\title{
Development of Extraction Method of Polycyclic Aromatic Hydrocarbons from Sunflower Oil
}

\author{
N.Y. Tereshchenko a, O.I. Khyzhan ${ }^{\text {b*, L.O. Kovshun }}{ }^{\mathrm{c}}$, V.I. Maksin ${ }^{\mathrm{d}}$, A.Y. Bobunov \\ ${ }^{a}$ Candidate of Chemical Science Associate Professor of Department of Medical and General \\ Chemistry, Bogomolets National Medical University, Peremohy Ave., Kyiv 02000, Ukraine \\ ${ }^{\mathrm{b}}$ Candidate of Chemical Science Associate Professor of Department of General, Organic and \\ Physical Chemistry, National University of Life and Environmental Sciences of Ukraine, Heroyiv \\ Oborony st., 15, Kyiv - 03041, Ukraine \\ ${ }^{\mathrm{c}}$ Doctor of Technical Sciences Head of Department of General, Organic and Physical Chemistry, \\ National University of Life and Environmental Sciences of Ukraine, Heroyiv Oborony st., 15, \\ Kyiv - 03041, Ukraine \\ ${ }^{\mathrm{d}}$ Doctor of Chemical Science Professor of Department of Analytical and Bioinorganic Chemistry \\ and Water Quality, National University of Life and Environmental Sciences of Ukraine, \\ Heroyiv Oborony st., 15, Kyiv - 03041, Ukraine \\ ${ }^{\mathrm{e}}$ Postgraduate, Department of Agrochemistry and Plant Production Quality, National University of \\ Life and Environmental Sciences of Ukraine, Heroyiv Oborony st., 15, Kyiv - 03041, Ukraine \\ olenakhyzhan@gmail.com
}

Keywords: polycyclic aromatic hydrocarbons, adsorption, activated charcoal, sunflower oil, chromatography.

Polycyclic aromatic hydrocarbons (PAHs) adsorption extraction process from sunflower oil on activated carbon was studied. Specific adsorption values on activated charcoal-xenobiotic system for compounds of benzo(a)anthracene, benzo(a)pyrene, benzo(e)pyrene, chrysene, benzo(b)fluoranthene and their mixtures were investigated. Influence of phase contact time of system, ratio of components on degree of PAHs extraction under isothermal conditions $\left(25 \pm 0.01^{\circ} \mathrm{C}\right)$ was studied. Degree of oil purification was controlled by method of high performance liquid chromatography with fluorescence detector (HPLC/FLD). Leaning on patterns found, optimal conditions for purification of raw sunflower oil from PAHs using activated charcoal and obtaining the matrix of sunflower oil proposed.

\section{Introduction}

The preliminary steps for implementation and using HACCP for food lines controlling are development and validation of actual laboratory methods. Results of laboratory methods usage should be compared with the Regulations of food production on each stage. For example, in vegetable oils production on-site, under all 
operating conditions and during all hours of operation, we need to use the matrixes of vegetable oils to ensure the representativity and accuracy. The simplest form of matrix obtaining is extraction cleaning of vegetable oil with modern sorbents. Under this idea, each xenobiotic from each vegetable oil can be separated.

Today, modern laboratory methods of research require the use of large quantities of expensive consumables and reagents imported into Ukraine. In previous studies of xenobiotics content in samples of vegetable raw materials and oils, as well as studying the physical and chemical properties of xenobiotics, possible ways of saving and optimizing the use of certain consumables were predicted, including through various methods of intensification of processes in the plant material-extractant system [4,5]. In addition to establishing the conditions for the intensification of extraction processes and the cost-effective use of consumables and solvents, a significant interest from the point of view of rationalization and ecologization of crop production test methods for the PAHs content is the liquid of plant origin - oil used as an extractant for the manufacturing of certain medicinal products [6]. However, the presence of xenobiotics with carcinogenic activity polycyclic aromatic hydrocarbons in the sunflower oil limits its use as an extractant [7]. The well-known industrial process of maximally complete purification of sunflower oil from xenobiotics allows to obtain refined oil of the mark "D", in which there are still xenobiotics at the level of $1 \mathrm{mcg} / \mathrm{kg}$. The use of mark "D" oil for the manufacture of medicines creates the preconditions for the content of trace amounts of xenobiotics of the PAHs group in the composition of the medicinal product.

The industrial oil purification from xenobiotics occurs with the use of various sorbents [8-10], among which there are no data on the use of inexpensive, accessible and known enterosorbent - activated carbon used to bind xenobiotics and toxins in the gastrointestinal tract $[11,12]$.

It is known that the chemical composition of unrefined oil or raw oil is characterized by the presence of xenobiotics of the PAHs group $[1,2]$, free fatty acids, phosphatides, natural waxes, natural vitamins, aromatic substances and the content of trace amounts of water [13]. On the appearance, raw oil is cloudy and not transparent, due to the significant content of waxes and phosphatides. In the process of hydration and neutralization, deodorization, bleaching and freezing the oil, the residues of related substances are eliminated, as well as the existing impurities are excluded, the oil becomes transparent and odorless. However, xenobiotics such as PAHs are not completely removed from the raw oil and residual PAHs quantities are allowed in the refined sunflower oil. Order of Ministry of Health of Ukraine No. 368 of May 13, 2013 “On Approval of the State Hygiene Rules and Norms" establishes a permissible content of benzo (a) 
pyrene not more than $2 \mathrm{mcg} / \mathrm{kg}$ and $10 \mathrm{mcg} / \mathrm{kg}$ - maximum total content of three PAHss (benzo (a) anthracene, benzo (a) pyrene, benzo (b) fluoranthene), but for dietary and baby food edible oils, the residual content of any of the above substances, or the total content of the PAHs group, may not exceed $1 \mathrm{mcg} / \mathrm{kg}$. Analyzing the content norms, it can be assumed that whitening clays (chemical compounds $\mathrm{Al}_{2} \mathrm{O}_{3}$ and $\mathrm{nSiO}_{2}$ ) and their mixtures with activated carbon during the refining process can remove all the compounds of the PAHs group, however, there are no references in the literature to the conditions of the refining process which lead to residual PAHs content ( $1 \mathrm{mcg} / \mathrm{kg})$.

Activated carbon has a high porosity. The surface area of one gram of activated carbon can range from 500 to $2200 \mathrm{~m}^{2}$. The pore radius can be from 0.2 to $200 \mathrm{~nm}$, mainly the adsorption capacity of activated carbon is determined by pores of size 0.5-1.6 nm, which are commensurate with the size of the adsorbed molecules [14]. Activated carbon is now widely used for the sorption of chemical compounds of anthropogenic origin or as an enterosorbent of toxins [11,12]. The process of extracting chemical compounds from different activated carbon systems is due to their absorption and retention by the active sites of the adsorbent. This process is usually explained by the induction of physical interaction between the active sites of the sorbent and xenobiotic molecules due to the weak Van der Waals forces. But under certain conditions, chemical reactions on the surface of the sorbent can also occur, which increase the purification efficiency due to chemisorption of xenobiotic, it is also possible for both processes to occur, physical and chemical sorption, which greatly enhances the action of the sorbent and increases the degree of purification of the object from xenobiotics. The most studied is the use of activated carbon for removing xenobiotics of organic nature, such as phenol, benzene, most petroleum products, chlorine and organophosphorus pesticides, polycyclic aromatic hydrocarbons from a solvent of inorganic nature - water.

\section{Experimental part}

The purpose of this work was to study the conditions and to establish the optimal conditions for the complete separation of polycyclic aromatic hydrocarbons from the raw oil by adsorption on activated carbon method.

\section{Materials and methods}

Samples of unrefined and refined sunflower oil were used in the work, which quality indicators corresponded to DSTU 4492:2017. For the separation from the raw oil of wax and phosphatides, as well as the sorbent at the stage of study of the adsorption process, was used the method of centrifugation at $4^{\circ} \mathrm{C}$ and vacuum filtration at room temperature using a nylon filter with a cell diameter of $0.46 \mathrm{mcm}$. The process of xenobiotic extraction was carried out by maceration, intensified by the action of temperature $\left(25^{\circ} \mathrm{C}\right)$ and constant stirring at a 
speed of $200 \mathrm{rpm}$. The work used solvents of qualification "for chromatography": acetone, methanol, isopropanol, acetonitrile, deionized water, orthophosphoric acid, solutions of analytical standards of PAHs in acetonitrile and isopropanol. Activated carbon was used as the sorbent (DSTU EN 12915-1:2004), having a developed overall porosity, a significant amount of specific absorbent surface (about $1000 \mathrm{~m}^{2}$ in one gram of carbon). Samples were handled in accordance with the methods developed by the ULQSP AIC. Xenobiotic content of the oil was determined by high performance liquid chromatography with fluorescence detection (HPLC / FLD) on an HPLC UltiMate $3000 \times 2$ Dual pump from Dionex equipped with SUPELCOSIL LC-PAH columns. In the chromatographic control of PAHs, a gradient elution mode was used. The first 20 minutes PAHs were eluted with a mixture of acetonitrile: deionized water $(4: 1)$ at a flow rate of 0.4 $\mathrm{cm}^{3} / \mathrm{min}$, for the next 5 minutes, the eluent was automatically replaced with $100 \%$ acetonitrile and the flow rate was increased to $1.0 \mathrm{~cm}^{3} / \mathrm{min}$. Acetonitrile was supplied to the system for 30 minutes, then for 5 minutes, with a gradual decrease in flow rate from $1.0 \mathrm{~cm}^{3} / \mathrm{min}$ to 0.4 $\mathrm{cm}^{3} / \mathrm{min}$, acetonitrile was replaced by a mixture of acetonitrile: deionized water (4: 1), which used for 10 minutes to condition the column. The control of the separation of PAH mixtures on chromatographic columns was carried out using a fluorescence detector tuned to measure $\mathrm{PAH}$ signals at $\lambda \mathrm{exc}=290 \mathrm{~nm}, \lambda$ emission $=430 \mathrm{~nm}$.

Cromeleon 6.0 software and MS Excel software were used to identify xenobiotic analytical signals and mathematically calculate the values that characterize the PAHs extraction process from oil $[1,2]$.

\section{Sampling}

Sampling was performed from tanks in accordance with the methodology of DSTU ISO 661: 2004. To create representative samples of refined and unrefined oil, the method of DSTU ISO 661: 2004 was used in sampling during storage of oil in storage tanks. In the laboratory, before the start of the study, oil samples (refined and unrefined) were marked, refined oil had the identification mark "p", not refined "c".

Oil samples were subjected to organoleptic and visual analysis. Raw oil in the state of aggregation is a liquid, viscous yellow-amber slurry, the suspended phase has a color from light brown to dark brown, the suspended mechanical impurities are evenly distributed throughout the sample volume. The suspension is capable of delamination during settling in the tank. The sample volume of one liter, which is placed in a measuring cylinder per liter, delaminates for 140 - 800 hours, depending on the dispersion, content and volume fraction of impurities. The use of the centrifugation method at $4^{\circ} \mathrm{C}$ and the vacuum filtration method at room temperature with the use of nylon filter with cell diameter of $0.46 \mathrm{mcm}$ allow separation of mechanical impurities from 
one liter of raw oil in 2.5 hours. The mechanical impurity oil is subject to the initial level of xenobiotics content. According to the results of the chromatographic analysis, all the samples of oil contain mixtures of polycyclic aromatic hydrocarbons: benzo (a) anthracene (BaA), benzo (a) pyrene (BaP), benzo (e) pyrene (BEP), benz (b) fluoranthene (BBF), chrysene (Chr). The established content of xenobiotics in oil are shown in table 1.

Table 1. Results of measurement of PAHs content in samples of raw sunflower oil

\begin{tabular}{|c|c|c|c|c|c|}
\hline \multirow{2}{*}{$\begin{array}{c}\text { Sample serial } \\
\text { number }\end{array}$} & \multicolumn{5}{|c|}{ Xenobiotics content, $\mathrm{mcg} / \mathrm{kg}$} \\
\cline { 2 - 6 } & $\mathrm{BaA}$ & $\mathrm{BaP}$ & $\mathrm{BeP}$ & $\mathrm{BBF}$ & $\mathrm{Chr}$ \\
\hline $1-\mathrm{p}$ & $0.5 \pm 0.1$ & $0.9 \pm 0.3$ & $1.2 \pm 0.2$ & $1.0 \pm 0.2$ & $0.9 \pm 0.2$ \\
\hline $2-\mathrm{p}$ & $2.7 \pm 0.4$ & $2.1 \pm 0.4$ & $3.1 \pm 0.6$ & $1.9 \pm 0.3$ & $2.4 \pm 0.5$ \\
\hline 3-c & $5.3 \pm 0.5$ & $4.2 \pm 0.8$ & $4.4 \pm 0.8$ & $3.9 \pm 0.6$ & $3.7 \pm 0.5$ \\
\hline 4-c & $5.9 \pm 0.7$ & $5.0 \pm 0.9$ & $5.4 \pm 0.6$ & $5.9 \pm 0.6$ & $4.1 \pm 0.5$ \\
\hline 5-c & $4.2 \pm 0.5$ & $6.3 \pm 1.1$ & $6.7 \pm 0.9$ & $4.7 \pm 0.4$ & $5.5 \pm 0.6$ \\
\hline 6-c & $7.3 \pm 0.6$ & $8.2 \pm 1.7$ & $9.2 \pm 0.9$ & $7.8 \pm 0.9$ & $8.3 \pm 0.9$ \\
\hline $7-\mathrm{c}$ & $8.7 \pm 1.2$ & $10.6 \pm 2.1$ & $9.8 \pm 1.7$ & $10.0 \pm 1.5$ & $9.7 \pm 1.3$ \\
\hline 8-c & $11.5 \pm 1.1$ & $14.9 \pm 1.4$ & $13.2 \pm 1.5$ & $9.4 \pm 0.9$ & $9.9 \pm 1.2$ \\
\hline 9-c & $12.4 \pm 1.1$ & $17.1 \pm 1.9$ & $14.5 \pm 1.5$ & $16.3 \pm 1.7$ & $17.3 \pm 1.5$ \\
\hline $10-c$ & $25.1 \pm 2.4$ & $23.2 \pm 1.8$ & $18.3 \pm 1.7$ & $21.2 \pm 2.1$ & $20.8 \pm 2.1$ \\
\hline
\end{tabular}

From table 1 it can be seen that the selected refined oil samples contain different amounts of xenobiotics. Samples № 1-p and № 2-p are characterized by the content of BEP and the amount of PAHs residues at the level of established standards for food oils brand "D" and "P" (Order of the Ministry of Health of Ukraine No. 368 of 13.05.2013). Other samples of raw oil studied in the work and listed in table 1, are characterized by exceeding the allowable levels of PAHs content. Samples of oils No. 7-c - 10-c are characterized by the content of BEP, which is 5-11 times higher than the permissible content of this xenobiotic in edible oils, analysis of oils with a high content of PAHs overloads the chromatographic column and reduces its term of operation.

Since sample №1 contains the least amount of xenobiotics, it was used to create model systems formed by artificially enriching oil with xenobiotics. Samples No. 7-c-10-c were used to test the effectiveness of the adsorbed PAHs extraction conditions under study.

Sample № 1-p was used in the work to create seven model systems in three marked parallels 
that were marked and used to investigate the sorption properties of activated carbon. Analytical standards of individual PAHs were introduced into the first five model systems in order to create in the oil the content of one of the target xenobiotics at the level of $2.0 \pm 0.2 \mu \mathrm{g} / \mathrm{kg}$. For example, from table 1 it can be seen that in sample №1-p, before its enrichment with BaA, the content of this xenobiotic was $0.5 \pm 0.1 \mu \mathrm{g} /$ $\mathrm{kg}$, and after enrichment (Table 2) the content of $\mathrm{BaA}$ was artificially increased to $2.0 \pm 0.4 \mu \mathrm{g} /$ $\mathrm{kg}$. It should be noted that the creation of model systems shown in table 2, from the sample №1-p occurred solely through the introduction of individual xenobiotics from their analytical standards.

The PAHs content of the model systems was investigated by HPLC / FLD, mentioned above in the section "Materials and methods". The set values of content $\left(\mathrm{c}_{0}\right)$ characterize the artificially enriched sample (Table 2) prepared for the test series.

Table 2. Results of measurement of PAHs content in an artificially enriched sample of sunflower raw oil No. 1-p

\begin{tabular}{|c|c|c|c|c|c|c|}
\hline \multirow{2}{*}{ Sample code } & \multicolumn{5}{|c|}{ Xenobiotics content $\left(\mathrm{c}_{0}\right), \mathrm{mcg} / \mathrm{kg}$} \\
\cline { 2 - 7 } & BaA & BaP & BeP & BBF & Chr & $\begin{array}{c}\text { The sum of 5 } \\
\text { PAHs }\end{array}$ \\
\hline 1 -p A 1 & $2.0 \pm 0.4$ & $0.9 \pm 0.3$ & $1.2 \pm 0.2$ & $1.0 \pm 0.2$ & $0.9 \pm 0.2$ & $6.0 \pm 1.1$ \\
\hline 1 -p P 1 & $0.5 \pm 0.1$ & $2.0 \pm 0.2$ & $1.2 \pm 0.2$ & $1.0 \pm 0.2$ & $0.9 \pm 0.2$ & $5.6 \pm 0.9$ \\
\hline 1 -p E 1 & $0.5 \pm 0.2$ & $0.9 \pm 0.3$ & $2.0 \pm 0.3$ & $1.0 \pm 0.2$ & $0.9 \pm 0.2$ & $5.3 \pm 0.8$ \\
\hline 1 -p F 1 & $0.5 \pm 0.1$ & $0.9 \pm 0.3$ & $1.2 \pm 0.3$ & $2.0 \pm 0.3$ & $0.9 \pm 0.2$ & $5.5 \pm 0.8$ \\
\hline $1-p$ Chr 1 & $0.5 \pm 0.2$ & $0.9 \pm 0.3$ & $1.2 \pm 0.3$ & $1.0 \pm 0.2$ & $2.0 \pm 0.2$ & $5.6 \pm 0.8$ \\
\hline $1-p$ A 2 & $2.0 \pm 0.2$ & $0.9 \pm 0.4$ & $1.2 \pm 0.3$ & $1.0 \pm 0.3$ & $0.9 \pm 0.2$ & $6.0 \pm 1.3$ \\
\hline $1-p$ P 2 & $0.5 \pm 0.1$ & $2.0 \pm 0.2$ & $1.2 \pm 0.2$ & $1.0 \pm 0.1$ & $0.9 \pm 0.1$ & $5.6 \pm 0.6$ \\
\hline $1-p$ E 2 & $0.5 \pm 0.1$ & $0.9 \pm 0.2$ & $2.0 \pm 0.2$ & $1.0 \pm 0.1$ & $1.0 \pm 0.2$ & $5.4 \pm 0.5$ \\
\hline $1-p$ F 2 & $0.5 \pm 0.1$ & $0.9 \pm 0.1$ & $1.2 \pm 0.2$ & $2.0 \pm 0.2$ & $0.9 \pm 0.1$ & $5.5 \pm 0.6$ \\
\hline $1-p$ Chr 2 & $0.6 \pm 0.2$ & $0.8 \pm 0.2$ & $1.1 \pm 0.2$ & $0.9 \pm 0.2$ & $2.0 \pm 0.3$ & $5.4 \pm 0.6$ \\
\hline
\end{tabular}

As can be seen from Table 2, the artificially generated total xenobiotic content in the experimental series of samples is stable within the error of the test method and averages $5.6 \pm 0.8 \mathrm{mcg} / \mathrm{kg}$, except for mixtures with priority xenobiotic benz (a) anthracene, with a total content of xenobiotics within $6.0 \pm 1.2 \mathrm{mcg}$ $/ \mathrm{kg}$.

The list of xenobiotics is individual for each sample in the series and is characterized by the priority content of one of the tested compounds. An artificial increase of the concentration of one 
of the xenobiotics is necessary to study the process of extraction of this compound on activated carbon at different ratios to other xenobiotics.

The first parallel of five model systems was divided into four equal portions of $200 \mathrm{~g}$, of which two parallel samples of $100 \mathrm{~g}$ were created. To each pair of parallel samples were added $1 \mathrm{~g}, 3.5 \mathrm{~g}, 6.5 \mathrm{~g}$ and 10 grams of activated carbon. The sorption process was carried out with constant stirring at room temperature $25^{\circ} \mathrm{C}$. Extraction of an aliquot of the oil mixture: activated carbon from the extraction system occurred every 30 minutes, an aliquot mass of 1.0 g. An aliquot by filtration was separated: the separated sorbent was returned to the extraction system, and the oil was transferred to the chromatographic study stage and the residual PAHs content (cn) was measured. The quantitative data obtained were used to calculate the specific adsorption (b) according to formula 1:

$$
b=\frac{m\left(c_{0}-c_{n}\right)}{\mathrm{k}}
$$

where: $\mathrm{m}$ is the mass of the sample (100 $\mathrm{g})$, $\mathrm{c}_{0}$ - is the PAHs content at the beginning of the study,

$\mathrm{c}_{\mathrm{n}}$ - equilibrium PAHs concentration in oil after a certain period of time,

$\mathrm{k}$ - is the mass of activated carbon added to the oil $(5.8,15,25 \mathrm{~g})$.

The equilibrium PAHs concentration in the oil decreased over a period of time, indicating that the sorption processes in the system progressed. The degree of extraction of xenobiotics is calculated according to formula 2 :

$$
C=\frac{\left(c_{0}-c_{n}\right)}{c_{0}}
$$

where: $\mathrm{c}_{0}$ - is the PAHs content at the beginning of the study,

$\mathrm{c}_{\mathrm{n}}$ - equilibrium PAHs concentration in oil after a certain period of time.

\section{Results and discussion}

Figure 1 shows the dependence of the specific sorption of activated carbon calculated according to formula 1 on the duration of the adsorption process, which occurred with the addition of different amounts of activated carbon. 


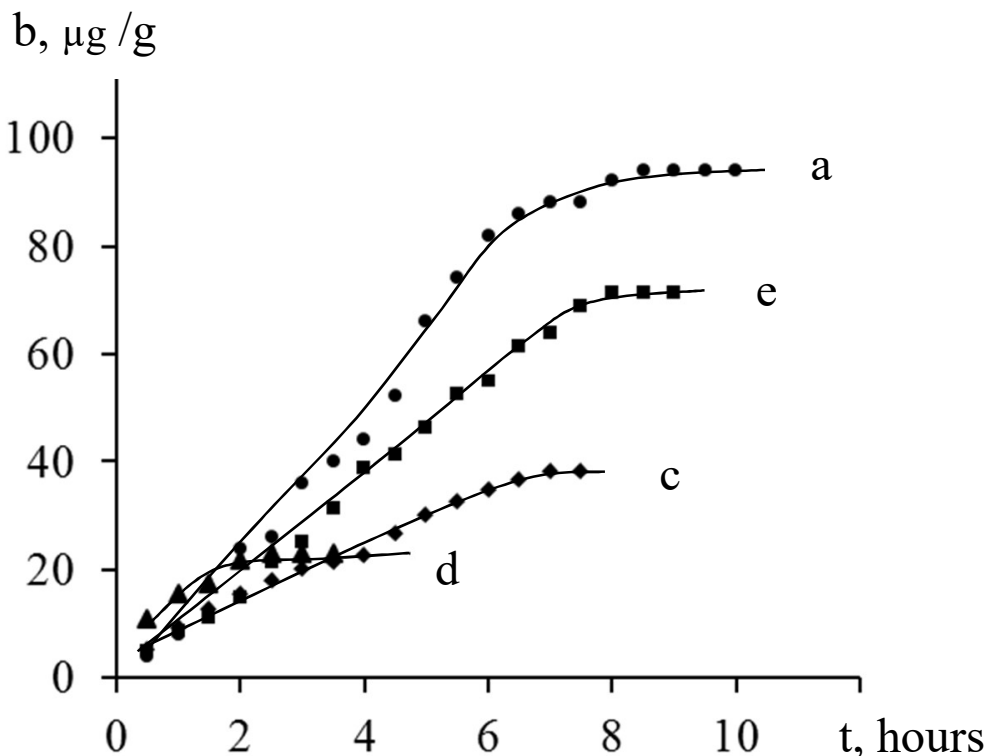

Figure 1. Dependence of the specific sorption of activated carbon on the duration of the process. Variable component - content of activated carbon:

$$
\mathrm{a}-1 \mathrm{~g}, \mathrm{e}-3.5 \mathrm{~g}, \mathrm{c}-6.5 \mathrm{~g}, \mathrm{~d}-10 \mathrm{~g}
$$

Initial total xenobiotic content of $560 \pm 80 \mathrm{ng}$, initial substrate mass $100 \mathrm{~g}, \mathrm{~T} 25^{\circ} \mathrm{C}$, stirring constant (200 rpm).

From Figure 1 it can be seen that with the increase in the mass of the sorbent, the sorption curve reaches the plateau in a shorter period of time, which indicates an increase in the speed of the adsorption process as the mass of the sorbent increases. The highest rate of PAHs removal from oil was achieved with the addition of 10 grams of activated carbon, however, this system is characterized by the lowest specific sorption rate, which indicates the low efficiency of sorbent use. The highest amount of specific sorption is achieved in a system with a minimum amount of sorbent, namely 1 gram, together with this amount of sorbent allows to remove only
$83 \%$ of the above mentioned initial amount of xenobiotics, that is not sufficient for the purification of oil.

Almost $99 \%$ of xenobiotics from the oil samples tested were extracted with a sorbent weighing 3.5 $\mathrm{g}$ or more. The average duration of the PAHs extraction process from one oil sample using 3.5 $\mathrm{g}$ of activated carbon is 8.5 hours.

Investigating the regularities of PAHs extraction with approximately the same hydrophobicity parameters [15], it was found that the lower the molecular weight of the priority xenobiotic, the more time was required to completely extract the PAHs from oil (Table 3). 
Table 3. Percentage of PAHs removal from sample 1-p A 2 and sample 1-p P 2 at $\mathrm{T} 25^{\circ} \mathrm{C}$ using $3.5 \mathrm{~g}$ of activated carbon

\begin{tabular}{|l|l|l|l|l|l|l|l|l|l|}
\hline t, min & \multirow{2}{*}{$\begin{array}{l}\text { sample } \\
1-\mathrm{p} \text { A 2 }\end{array}$} & 30 & 90 & 180 & 360 & 420 & 450 & 480 & 510 \\
\cline { 3 - 10 } w, \% & 5.3 & 14.0 & 24.4 & 52.1 & 75.3 & 86.4 & 93.5 & 100 \\
\hline \hline t, min & \multirow{2}{*}{$\begin{array}{l}\text { sample } \\
1-\mathrm{p} \text { P 2 }\end{array}$} & 30 & 90 & 180 & 360 & 420 & 450 & 480 & 510 \\
\cline { 4 - 11 } & & 8.9 & 19.2 & 36.2 & 77.6 & 89.6 & 98.1 & 100 & 100 \\
\hline
\end{tabular}

\section{Conclusions}

As can be seen from Table 3 in the first 30 minutes of solid phase extraction from sample 1p A2 with a priority content of $\mathrm{BaA}(\mathrm{M} \mathrm{BaA}=$ $228 \mathrm{~mol} / \mathrm{g}$ ), $5.3 \%$ of xenobiotics were removed, 510 minutes were required to completely remove the PAHs from this sample.

8.9\% PAHs was removed from sample 1-p P2 with priority content of $\mathrm{BaP}(\mathrm{M} \mathrm{BaP}=252 \mathrm{~mol} /$ h) in the first 30 minutes of the process, which is $3.6 \%$ more than from sample 1-p A 2 during this period of time. The dynamics of increasing the number of xenobiotics retrieved for a sample with a priority content of xenobiotic with a molecular weight of $252 \mathrm{~mol} / \mathrm{g}$, compared to the sample containing a priority xenobiotic with a molecular weight of $228 \mathrm{~mol} / \mathrm{g}$, is maintained throughout the process. The total contact time of the oil-activated charcoal phases required for complete PAHs removal from sample 1-p P2 is 480 minutes, which is 30 minutes less than the time taken to extract PAHs from the previous sample.
Using activated carbon in the work was achieved purification of crude oil samples №№ 3-c - 10-c to a total final content of 5 surfactants $\leq 2.5 \pm 0.5$ $\mu \mathrm{g} / \mathrm{kg}$.

Thus, the optimal conditions of the process of adsorption of PAHs on activated carbon are achieved in isothermal conditions $\left(25^{\circ} \mathrm{C}\right)$ with constant stirring of the system at a speed of 200 revolutions per minute. The ratio of the mass of the sorbent to the mass of raw oil is variable and depends on the total content of xenobiotics, for every $560 \pm 80 \mathrm{ng}$ xenobiotics of the surfactant group must be introduced into the system $1 \mathrm{~g}$ of activated carbon, the average sorption time is 510 \pm 30 minutes

\section{References}

[1] Nesterova L. O., Hrybova N. Y., Khyzhan O. I., Ushkalov V. O. Development of controls method for the isomers of polycyclic aromatic hydrocarbons in vegetable oils. Scientific Journal of National University of Life and Environmental Sciences of Ukraine. Series: Agronomy, 2018, 286, 312-320.

[2] Hrybova N. Yu.. Xenobiotics of PAHss group is extracted from sunflower seeds. Scientific Journal of National University of Life and Environmental Sciences of Ukraine. Series: Agronomy, 2018, 294, 209-218. 
[3] Grybova N. Y., Nesterova L. O., Khyzhan O. I., Ushkalov V.O., Maksin V.I. . Determination of Polycyclic Carbohydrates in Atmospheric Water by the Method of Chromatography. Journal of Water Chemistry and Technology, 2018, 40 (5), 297-301.

[4] Gribova N. Yu., Filippenko T. A., Nikolaevskii A. N., Khizhan E. I., Bobyleva O. V. Effects of ultrasound on the extraction of antioxidants from bearberry (Arctostaphylos adans) leaves. Pharmaceutical Chemistry Journal, 2008, 42 (10), 593-595.

[5] Hrybova N. Y.. Vlijanie uslovij ekstrakcii na antioksidantnye svojstva izvlechennyh fitofenolov. Metody i ob"ekty himicheskogo analiza, 2012, (7,\# 4), 202-206

[6] 6. Bysaha, Ye. I., Olijnyk, S. V., Vyshnevska, L. I., Herasymova, I. V., Lytvynenko, Ye. Yu. Xromatohrafichni doslidzhennya olijnyx ekstraktiv z travy selery paxuchoyi ta pasternaku posivnoho, 2017.

[7] Toxicological Review of Benzo[a]pyrene. Review of EPA's Draft Assessment. U.S. Environmental Protection Agency. Washington: EPA, 2017. 97 p.

[8] Huang, Y., Zhou, Q., \& Xie, G. (). Development of micro-solid phase extraction with titanate nanotube array modified by cetyltrimethylammonium bromide for sensitive determination of polycyclic aromatic hydrocarbons from environmental water samples. Journal of hazardous materials, 2011, 193, 82-89.

[9] A Sposib vydalennya policyklichnyx aromatychnyx vuhlevodniv. Ukraine patent 104865, 25.03.2014, Bul. № 6, 2014.

[10] Sposib vyznachennya vmistu policyklichnyh aromatychnyh ta aromatychnyh vuhlevodniv u produktax, shho mistyat" harchovi oliyi ta zhyry. Ukraine patent 82364, 10.04.2008, Bul. № 7, 2008.

[11] Koscevych, N. M. Vyznachennya antymikrobnoyi ta adsorbcijnoyi aktyvnosti vuhillya, zbahachenoho fitoekstraktamy. Problemy ekolohichnoyi biotexnolohiyi, 2015, (1).

[12] Khrokalo, L. A., Pylypenko, T. M., \& Verves, K. Y.. Additional properties of pharmaceutical preparations: active coal and white coal. Naukovyj zhurnal «Biolohichni systemy: teoriya ta innovaciyi», 2018, (287), 1219-135.

[13] Osejko, M. I.. Tekhnologiya roslynnykh olii. Kiev: Varta, 280.

[14] DSTU EN 12915-1:2004, Materialy dlya ochyshhennya vody, pryznachenoyi dlya spozhyvannya lyudynoyu. Hranulovane aktyvovane vuhillya. Chastyna 1. Chyste hranulovane aktyvovane vuhillya. (EN 12915-1:2003, IDT)

[15] Derun, Yu. A. et al. Rozrahunky parametriv hidrofobnosti izomeriv benzopirenu dlya poshuku optymal"nyh umov vymiryuvannya jih vmistu v atmosfernij vodi. Himichni problemy sohodennya, 2018, (S.1), p. 14. Available from: http://jhps.donnu.edu.ua/article/view/5159. 